\title{
ИССЛЕДОВАНИЕ РЕАКЦИИ ТЕРМОДЕСТРУКЦИИ ЦЕЛЛЮЛОЗЫ В ПРИСУТСТВИИ НЕОРГАНИЧЕСКИХ СОЕДИНЕНИЙ МЕТОДОМ СТУПЕНЧАТОЙ ПИРОЛИЗНОЙ ГАЗОВОЙ ХРОМАТОГРАФИИ
}

Исследование процесса термодеструкции обработанных целлюлозных материалов имеет большое практическое значение. В настоящее время все увеличивается выпуск «облагороженных», различными добавками целлюлозных материалов в целях придания им повышенной огне- и термостойкости, стабильности от света, старения и т. д.

Известно применение некоторых неорганических соединений в качестве антипиренов - веществ, повышающих огнестойкость обрабатываемого материала. Различными солями пользуются и для обработки гидратцеллюлозных нитей до их карбонизации для получения углеродных волокон.

Требования для обоих случаев - на огнестойкий материал и на сырье для углеродных волокон - очень близкие. Для достижения обеих целей важно, чтобы в продуктах пиролиза обработанных целлюлозных материалов было больше воды и меньше углеродсодержащих веществ. Для углеродных материалов это требование очевидно, ибо целлюлоза, как и все углеводы, состоит из углерода, водорода и кислорода, причем соотношение двух последних элементов (2:1) такое же, как и в воде. Это значит, что наибольший выход углеродного остатка был бы достигнут, если бы термодеструкция целлюлозы представляла собой чистую дегидратацию. Применение неорганических солей для обработки сырья для углеродных волокон выгодно и с экономической точки зрения: они обычно намного дешевле, чем сложные органические антипирены.

Для огнестойкости целлюлозных материалов тоже важно, чтобы из них выделилось больше пиролизной воды. Когда смесь пиролизньіх газов больше содержит воды (негорючего вещества), то для ее горения надо больше кислорода. Так увеличивается кислородный индекс, а следовательно, и огнестойкость материала. Даже в случае возгорания пиролизных газов их горение при повышенном содержании воды протекает с меньшим выделением тепла. Это уменьшает пиролиз твердого материала, и пламя становится менее устойчивым.

\section{Экспериментальная часть}

Исследование обработанных целлюлозных материалов проводили методом ступенчатой пиролизной газовой хроматографии (СПГХ). Методика и аппаратура описаны в [1]. Образцы готовили пропиткой предварительно промытого гидратцеллюлозного материала в растворах соответствующих солей. В приготовленный 0,5\%-ный солевой раствор по- 
гружали на. 5 мин 5 г гидратцеллюлозы. Материал доставали из раствора, выжимали до веса 15 г и высушивали при комнатной температуре в течение 48 ч.

Полученные материалы содержали около $1 \%$ соответствующих coлей. Точное содержание соли не определяли, так как в целлюлозу входит примерно столько соли, сколько ее увлекается вместе с раствором [ $\left.{ }^{2}\right]$ (в данном случае 0,05 г на 5 г гидратцеллюлозы) и к тому же для выяснения каталитического действия солей небольшие колебания в их количествах не играют существенной роли.

Для исследования брали навеску 5 мг и подвергали ее многократному пиролизу, ступенчато поднимая температуру через каждые $10^{\circ}$ в интервале от 100 до $330^{\circ} \mathrm{C}$. После каждого пиролиза газохроматографически определяли, сколько выделилось воды, окиси углерода и двуокиси углерода. На основе полученных данных определяли суммарные выходы, температуры максимального выделіения и энергии активации выделения указанных продуктов пиролиза. Энергии активации рассчитывали по формуле Аррениуса на микро-ЭВМ по“методике, опубликованной в [3].

\section{Результаты и обсуждение}

Разные неорганические соли влияют на термодеструкцию гидратцеллюлозы очень по-разному (см. рисунок и табл. 1,2 ). Но объединяет их одна черта - все они значительно или ненамного увеличивают количество выделяющейся воды. А так как и выходы $\mathrm{CO}$ и $\mathrm{CO}_{2}$ тоже весьма неодинаковы, значит, не все исследованные соли можно считать антипиренами или полезными добавками в сырье для изготовления углеродных материалов. Это наглядно видно на примерах, приведенных на рисунке. Так, добавленный к гидратцеллюлозным волокнам $\mathrm{NH}_{4} \mathrm{Cl}$ вызывает их практически чистую дегидратацию уже на первом этапе термодеструкции с полным сохранением углеродного скелета, a $\mathrm{Na}_{3} \mathrm{PO}_{4}$, хотя и способствует даже большему выделению воды, чем $\mathrm{NH}_{4} \mathrm{Cl}$, но одновременно катализирует выделение $\mathrm{CO}$ и $\mathrm{CO}_{2}$, а следовательно, и разрушает углеродный скелет.

Влияние $\mathrm{NH}_{4} \mathrm{Cl}$ на термодеструкцию целлюлозы исследовалось многими авторами, так как в практике выпуска углеродных волокон его чаще других солей используют в качестве добавки. Тем не менее большинство исследователей либо вообще не видят существенной разницы в существе двух этапов процесса, либо должны доказывать дегидратационную основу первого пика на ДТГ-кривой косвенными методами (ИК-спектрами и т. д.) [ [4]. Например, есть мнения, что $\mathrm{NH}_{4} \mathrm{Cl}$ «увеличивает выход жидких продуктов типа левоглюкозана» [2], хотя давно доказано, что любые неорганические соли резко уменьшают выход левоглюкозана- [5].

Судя по экспериментальным и литературным данным [ $\left.{ }^{6}\right]$, можно предположить, что выделяющийся при термодеструкции $\mathrm{NH}_{4} \mathrm{Cl}$ хлористый водород катализирует межмолекулярную дегидратацию целлюлозы. На первом этапе пиролиза выделяется более одной молекулы воды на каждое элементарное звено целлюлозы. Образуется трехмерная сшитая структура, которая далее разлагается довольно медленно, сохраняет хорошую ориентацию молекул и дает при дальнейшем нагреве углеродное волокно хорошего качества и с большим выходом.

Роль $\mathrm{NaCl}$ намного меньше. Единственными заслуживающими внимания изменениями можно считать небольшое увеличение количества выделяющейся воды и снижение температур максимального выхода газовых продуктов. Известно [6], что $\mathrm{NaCl}$ не является антипиреном и не влияет на кислородный индекс целлюлозы. Хотя в [5] и показана 

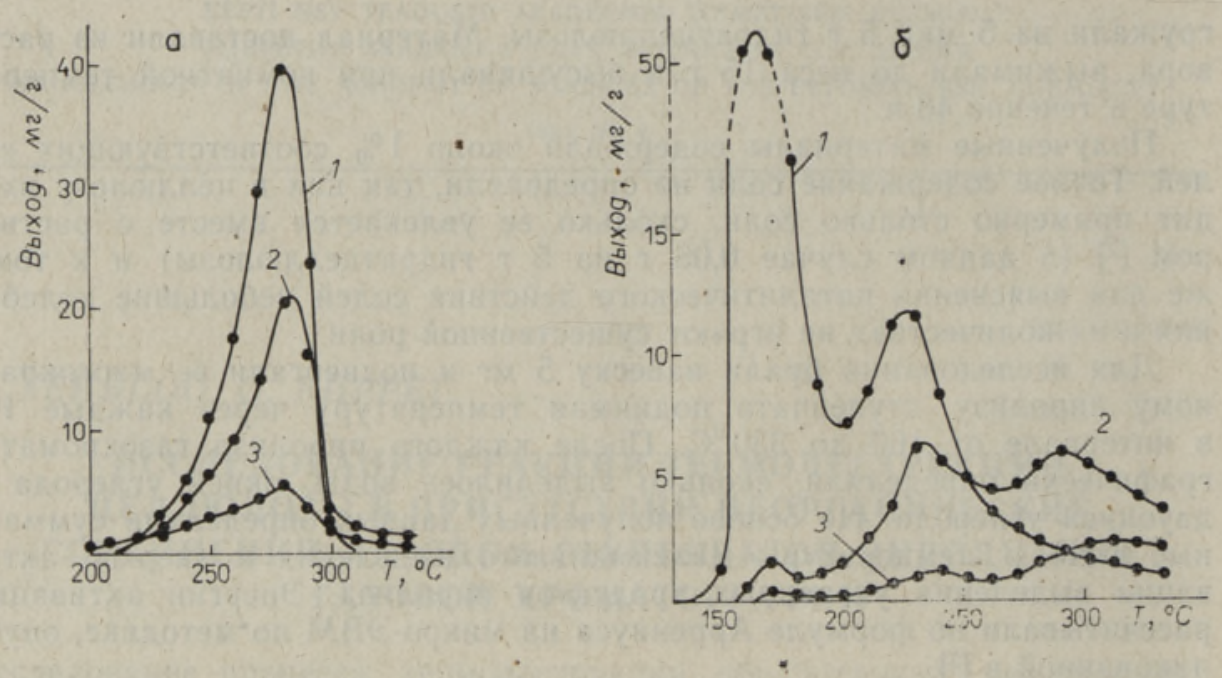

Выделение $\mathrm{H}_{2} \mathrm{O}(I), \mathrm{CO}_{2}$ (2) и $\mathrm{CO}$ (3) при пиролизе методом СПГХ необработанного вискозного волокна (a), волокна, содержащего $1 \%$

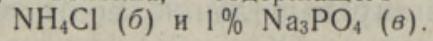

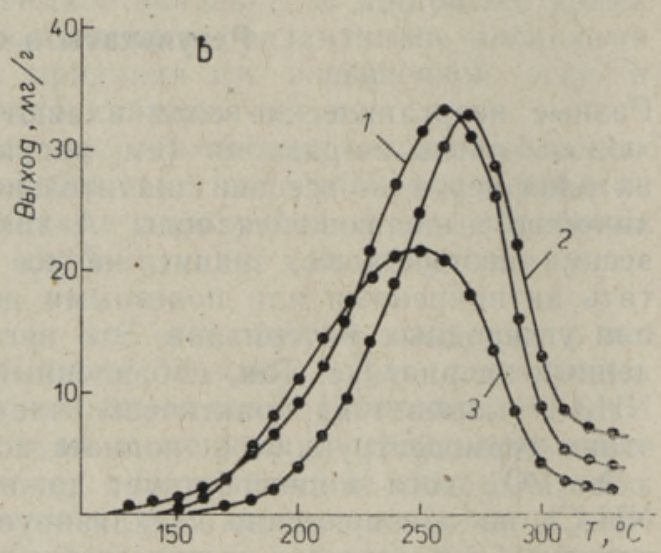

зависимость выхода левоглюкозана от наличия $\mathrm{NaCl}$, те опыты проводились в условиях глубокого вакуума. Согласно [ $\left.{ }^{7}\right]$, левоглюкозан является основным горючим продуктом пиролиза целлюлозы. Но если бы и в реальных условиях $\mathrm{NaCl}$ оказывал влияние на его выход, изменялся бы и кислородный индекс, что на самом деле не наблюдается.

Еще меньшую роль в термодеструкции целлюлозы играют $\mathrm{NH}_{4} \mathrm{HCO}_{3}$ и $\left(\mathrm{NH}_{4}\right)_{2} \mathrm{CO}_{3}$. О том, что влияние последнего сводится практически к нулю, отмечалось и в [8].

Причина кроется, видимо, в том, что эти соли, покрывая гидратцеллюлозные нити в виде обложки [ $\left.{ }^{2}\right]$, легко разлагаются и улетучнваются при очень низких температурах, даже при комнатных.

В [ $\left.{ }^{9}\right]$ показано уменьшение энергии активации суммарного процесса термодеструкции целлюлозы под влиянием $\mathrm{NaHCO}_{3}$ почти в полтора раза. Такие же тенденции показывают и наши эксперименты, хотя проявляются они гораздо слабее из-за малых количеств введенной соли.

Значительно большее влияние оказывает $\mathrm{Na}_{2} \mathrm{CO}_{3}$, особенно на энергии активации выделения газовых продуктов и на суммарный выход $\mathrm{CO}$, а также $\mathrm{CO}_{2}$ : Известно, что в большом количестве $\mathrm{Na}_{2} \mathrm{CO}_{3}$ влияет как антипирен и довольно значительно увеличивает кислородный индекс материала. Наши результаты показывают, что имеет место ката- 
Количественные выходы и температуры максимального выделения легких продуктов пиролиза из гидратцеллюлозных волокон, содержащих по $1 \%$ неорганических солей

\begin{tabular}{|c|c|c|c|c|c|c|}
\hline \multirow[b]{2}{*}{ Образец } & \multicolumn{2}{|c|}{$\mathrm{CO}$} & \multicolumn{2}{|c|}{$\mathrm{CO}_{2}$} & \multicolumn{2}{|c|}{ - $\mathrm{H}_{2} \mathrm{O}$} \\
\hline & $\begin{array}{c}\text { выход, } \\
\text { ма/2 }\end{array}$ & $T_{\text {мaxc, }}{ }^{\circ} \mathrm{C}$ & $\begin{array}{c}\text { выход, } \\
\text { ма/а }\end{array}$ & $T_{\text {мaкс }}{ }^{\circ} \mathrm{C}$ & $\begin{array}{c}\text { выход, } \\
\text { ма/2 }\end{array}$ & $T_{\text {маке, }}^{{ }^{\circ} \mathrm{C}}$ \\
\hline $\begin{array}{l}\text { Исходный } \\
\mathrm{NH}_{4} \mathrm{Cl} \\
\mathrm{NH}_{4} \mathrm{HCO}_{3} \\
\left(\mathrm{NH}_{4}\right)_{2} \mathrm{CO}_{3} \\
\mathrm{NaCl} \\
\mathrm{Na}_{2} \mathrm{CO}_{3} \\
\mathrm{NaHCO}_{3} \\
\mathrm{Na}_{3} \mathrm{PO}_{4} \\
\mathrm{NaH}_{2} \mathrm{PO}_{4} \\
\mathrm{NH}_{4} \mathrm{H}_{2} \mathrm{PO}_{4}\end{array}$ & $\begin{array}{r}27,63 \\
17,94 \\
20,56 \\
19,21 \\
28,38 \\
70,50 \\
39,55 \\
150,68 \\
38,75 \\
36,21\end{array}$ & $\begin{array}{l}279 \\
238 \\
268 \\
276 \\
260 \\
255 \\
280 \\
249 \\
263 \\
\end{array}$ & $\begin{array}{r}81,17 \\
66,13 \\
74,73 \\
79,04 \\
93,82 \\
121,98 \\
93,55 \\
172,60 \\
105,36 \\
79,13\end{array}$ & $\begin{array}{l}281 \\
234 \\
269 \\
276 \\
262 \\
265 \\
287 \\
266 \\
266 \\
257 \\
\end{array}$ & $\begin{array}{l}132,24 \\
197,09 \\
140,42 \\
134,02 \\
151,59 \\
141,15 \\
147,09 \\
208,41 \\
199,60 \\
210,96\end{array}$ & $\begin{array}{c}279 \\
165 \text { и } 226 \\
268 \\
277 \\
260 \\
259 \\
285 \\
260 \\
262 \\
246\end{array}$ \\
\hline
\end{tabular}

Таблица 2

Энергии активации выделения легких продуктов пиролиза при термодеструкции обработанных гидратцеллюлозных материалов, ккал/моль

\begin{tabular}{l|c|c|c}
\hline \multicolumn{1}{c|}{ Образец } & $\mathrm{CO}$ & $\mathrm{CO}_{2}$ & $\mathrm{H}_{2} \mathrm{O}$ \\
\hline & & & \\
$\mathrm{Ncxодный}_{4} \mathrm{Cl}$ & $24,10 \pm 0,85$ & $34,74 \pm 0,73$ & $43,38 \pm 0,66$ \\
$\mathrm{NH}_{4} \mathrm{HCO}_{3}$ & $23,18 \pm 0,29$ & $31,06 \pm 0,52$ & $17,51 \pm 1,21$ \\
$\left(\mathrm{NH}_{4}\right)_{2} \mathrm{CO}_{3}$ & $23,24 \pm 1,10$ & $34,21 \pm 1,60$ & $49,39 \pm 1,49$ \\
$\mathrm{NaCl}$ & $26,18 \pm 0,83$ & $29,44 \pm 0,82$ & $42,49 \pm 0,94$ \\
$\mathrm{Na}_{2} \mathrm{CO}_{3}$ & $29,65 \pm 0,49$ & $35,24 \pm 1,53$ & $52,94 \pm 1,00$ \\
$\mathrm{NaHCO}_{3}$ & $18,03 \pm 0,70$ & $24,21 \pm 0,54$ & $27,28 \pm 1,02$ \\
$\mathrm{Na}_{3} \mathrm{PO}_{4}$ & $23,70 \pm 0,48$ & $31,93 \pm 0,42$ & $39,22 \pm 1,25$ \\
$\mathrm{NaH}_{2} \mathrm{PO}_{4}$ & $15,16 \pm 0,27$ & $23,10 \pm 0,29$ & $16,52 \pm 0,84$ \\
$\mathrm{NH}_{4} \mathrm{H}_{2} \mathrm{PO}_{4}$ & $27,70 \pm 1,48$ & $34,83 \pm 0,96$ & $34,45 \pm 0,83$ \\
& $20,24 \pm 1,08$ & $35,36 \pm 1,48$ & $29,46 \pm 0,78$
\end{tabular}

литическое разрушение глюкозидного цикла. Но делать какие-либо определенные выводы относительно механизма термодеструкции целлюлозы под влиянием $\mathrm{Na}_{2} \mathrm{CO}_{3}$ и возможностях ее практического применения еще рано, потому что данная система исследована мало.

Очень часто используют в качестве антипиренов фосфорсодержащие соединения, особенно фосфорорганические вещества или фосфорную кислоту []. Их общий принцип действия заключается в образовании полифосфорной кислоты и в ее дальнейшем дегидратирующем влиянии $[7,8]$.

Таков же механизм действия и $\mathrm{NH}_{4} \mathrm{H}_{2} \mathrm{PO}_{4}$. Как показывают наши экспериментальные данные, влияние этой соли проявляется главным образом в увеличении дегидратации, уменьшении энергии активации и снижении температуры максимума этой реакцин. В $\left.{ }^{9}\right]$ найдено большое увеличение кислородного индекса и угольного остатка, а в [10] отмечено уменьшение энергии активации суммарного процесса пиролиза примерно в полтора раза. Действие $\mathrm{NH}_{4} \mathrm{H}_{2} \mathrm{PO}_{4}$ как антипирена замечено нами и по выделению СО. Хотя выход СО даже немного увеличивается по сравнению с его выходом из необработанного материала, он не имеет максимума в исследуемой температурной области и выделяется небольшими количествами при всех температурах.

Полученные экспериментальные данные относительно фосфорнокис- 
Удаление С, О и Н из элементарного звена целлюлозы

в виде легких продуктов пиролиза

(количество атомов на каждое элементарное звено)

\begin{tabular}{l|c|c|c}
\hline \multicolumn{1}{c|}{ Образец } & $\mathrm{C}$ & $\mathrm{O}$ & $\mathrm{H}$ \\
\hline & & & \\
\hline $\mathrm{NH}_{4} \mathrm{Cl}$ & 0,46 & 1,95 & 2,38 \\
$\mathrm{NH}_{4} \mathrm{HCO}_{3}$ & 0,35 & 2,37 & 3,51 \\
$\left(\mathrm{NH}_{4}\right)_{2} \mathrm{CO}_{3}$ & 0,39 & 1,94 & 2,53 \\
$\mathrm{NaCl}$ & 0,40 & 1,90 & 2,41 \\
$\mathrm{Na}_{2} \mathrm{CO}_{3}$ & 0,51 & 2,22 & 2,72 \\
$\mathrm{NaHCO}_{3}$ & 0,85 & 2,57 & 2,54 \\
$\mathrm{Na}_{3} \mathrm{PO}_{4}$ & 0,57 & 2,25 & 2,64 \\
$\mathrm{NaH}_{2} \mathrm{PO}_{4}$ & 1,50 & 4,02 & 3,75 \\
$\mathrm{NH}_{4} \mathrm{H}_{2} \mathrm{PO}_{4}$ & 0,50 & 2,69 & 3,79 \\
& 0,61 & 2,80 & 3,60 \\
& & &
\end{tabular}

лых солей натрия вызывают некоторое удивление и представляют трудности для интерпретации, поскольку механизм их действия ранее не изучался.

$\mathrm{Na}_{3} \mathrm{PO}_{4}$ при исследуемых температурах термически совершенно стабилен. Трудно представить, как из него могла бы образоваться полифосфорная кислота. Тем не менее он очень сильно катализирует пиролиз целлюлозы, причем не только дегидратацию, как $\mathrm{NH}_{4} \mathrm{H}_{2} \mathrm{PO}_{4}$, но и разрушение самого углеродного скелета с большим выделением СО и $\mathrm{CO}_{2}$, а также значительно изменяет энергии активации выделения всех исследуемых продуктов.

$\mathrm{NaH}_{2} \mathrm{PO}_{4}$ катализирует реакцию дегидратации. Он так же, как и $\mathrm{Na}_{3} \mathrm{PO}_{4}$, увеличивает выделение $\mathrm{CO}$ и $\mathrm{CO}_{2}$, но несколько в меньшей мере и без влияния на энергетику этих процессов.

Исходя из вышеизложенного, а также из данных табл. 3 , можно заключить, что термодеструкция целлюлозы протекает в присутствни различных солей по-разному, т. е. говорить о влиянии общей зольности нет оснований. Единственная черта, присущая всем солям, это повышенный выход воды, которому, по-видимому, сопутствует значительно пониженный выход левоглюкозана - основного продукта деполимеризации.

Соли, катализирующие реакцию дегидратации и в то же время не оказывающие заметного влияния на выделение $\mathrm{CO}$ и $\mathrm{CO}_{2}$ (напр., $\mathrm{NH}_{4} \mathrm{Cl}$ и $\mathrm{NH}_{4} \mathrm{H}_{2} \mathrm{PO}_{4}$ ), можно рекомендовать в качестве добавок в сырье угольных волокон. Они вызывают внутри- и межмолекулярную сшивку целлюлозы и способствуют увеличению выхода угольного остатка, о чем, в частности, отмечалось в [ $\left.{ }^{9}\right]$.

И напротив, в производстве углеродных волокон следует избегать присутствия соды, а также веществ, из которых она может образоваться (напр., $\mathrm{NaOH}$ ). Такой вывод подсказывает поведение $\mathrm{Na}_{2} \mathrm{CO}_{3}$, которая хотя и несколько повышает выделение воды, но зато увеличивает удаление углерода в виде $\mathrm{CO}$ и $\mathrm{CO}_{2}$.

Трудно делать исчерпывающие выводы относительно влияння $\mathrm{Na}_{3} \mathrm{PO}_{4}$. В ее присутствии удаляется в виде легких газов полтора атома углерода из каждых шести в одном элементарном звене, но в то же время убывает и четыре атома кислорода из пяти возможных. Механизм действия данной соли требует дальнейшего исследования, так как он не вписывается в рамки существующих теорий.

B $[7,9]$ на основе серий опытов с различными количествами одной и той же дабавки сделан вывод о линейной зависимости между энер- 
гиями активации термодеструкции и кислородными индексами материалов. Однако данные наших экспериментов и приведенных в литературе не подтверждают корректной математической корреляции между кислородными индексами обработанных целлюлозных материалов и энергетическими и количественными данными о выходе продуктов пиролиза. Прослеживаются тенденции качественной корреляции между огнестойкостью и выделением воды, ее количеством и энергией актнвации дегидратации. Суммарный процесс термодеструкции целлюлозы слишком сложен, чтобы делать выводы о нем по кажущимся энергиям активации, полученным путем термогравиметрического анализа.

Энергии активации дегидратации целіюлозы имеют явно выраженные температурные пределы и могут для некоторых образцов описывать конкретные химические реакции, в то время как термогравимегрия оперирует «кажущимися» суммарными процессами.

\section{Л И Т Е Р А Т У Р А}

1. Heinsoo, E., Kogerman, A., Kirret, O., Coupek, J., Vilkova, S. Stepwise pyrolysis-gas chromatography of viscose fibres. - J. Anal. Appl. Pyrol., 1980, 2, N 2, $131-139$

2. Курневич Т. Н., Лойко Э. М., Скоропанов А. С., Зак В. Л., Зайчиков С. Г. Жуйкова Т. Н., Вечер А. А. Исследование поведения компонентов системы гидратцеллюлоза-хлорид аммония при повышенных температурах. - Деп. в ВИНИТИ 10.03.83. № 1246-83.

3. Хейнсоо Э. Ю., Кальюранд М. Р. Методы определения энергии активации термодеструкции целлюлозы по данным СПГХ. - В кн.: Четвертая научная конференция по аналитической химии Прибалтийских республик, Белорусской ССР и Калининградской области, I. Тезисы докл. Таллин, 1982, 273.

4. Гаврилов М. 3., Ермоленко Н. Н. Изучение влияния концентрации хлористого аммония в гидратцеллюлозе на процессы ее пиролиза. - Изв. АН БССР. Хим., 1977,22 , № $5,22-26$.

5. Голова О. П. Химические превращения целлюлозы при тепловом воздействии. Успехи химии, 1975,44 , № 8, $1454-1474$.

6. Einsele, U., Meyer, $P$., Herlinger, $H$. Zusammenhänge zwischen Dehydratisierungsreaktion und Flammenschutzeffekt bei Cellulosefasern. - Cellulose Chem. Technol., 1979, 13, N 1, 57-75.

7. Тюганова М. A., Копьев М. А., Кочаров С. А. Огнезащищенные текстильные материалы. - Ж. Всес. хим. о-ва им. Д. И. Менделеева. 1981, 26, № 4, 61-68

8. Kishore. K.. Mohandas, $K$. Action of phosphorus compounds on fire-retardancy of cellulosic materials. A Review. - Fire and Materials, 1982, 6, N 2, 54-58.

9. Tang, W. K., Neill, W. K. Effect of flame retardants on pyrolysis and combustion of a-cellulose. - J. Polym. Sci. C, 1964, N 6, 65-81.

10. Akita, K., Kase, M. Determination of kinetic parameters for pyrolysis of cellulose and cellulose treated with ammonium phosphate by differential thermal analysis and thermal gravimetric analysis. - J. Polym. Sci. A-1, 1967, N 5, 833-848.
Институт химии
Академии наук Эстонской ССР Поступила в редакцию
1/VI 1984

\section{E. HEINSOO, O. KIRRET}

\section{ANORGAANILISI SOOLI SISALDAVATE TSELLULOOSKIUDUDE TERMODESTRUKTSIOONI UURIMINE ASTMELISE PUROLUUSGAASIKROMATOGRAAFIA MEETODIL}

On uuritud mitmete naatriumi ja ammooniumi soolade mōju tsellulooskiudude termodestruktsioonile. Astmelise pürolüüsgaasikromatograafia meetodil on uuritud $\mathrm{CO}, \mathrm{CO}_{2}$ ja vee eraldumise kineetikat materjalide lagunemisel temperatuuril $100-330^{\circ} \mathrm{C}$ ning arvutatud vastavate reaktsioonide aktivatsioonienergiad.

On leitud, et kuigi kõik soolad suurendavad tselluloosi dehüdratatsiooni, on nende toimemehhanism erinev. Kõige tugevamini katalüüsivad nimetatud reaktsiooni $\mathrm{NH}_{4} \mathrm{Cl}$, $\mathrm{NH}_{4} \mathrm{H}_{2} \mathrm{PO}_{4}$ ja $\mathrm{Na}_{3} \mathrm{PO}_{4}$. 


\section{STEPWISE PYROLYSIS GAS CHROMATOGRAPHY STUDIES OF THERMODESTRUCTION REACTION \\ OF CELLULOSE CONTAINING INORGANIC SALTS}

Influence of some sodium and ammonium salts on the thermodestruction of cellulose fibres was studied. Kinetics of evolution of $\mathrm{CO}, \mathrm{CO}_{2}$ and water was determined in $100-330^{\circ} \mathrm{C}$ range, using the stepwise pyrolysis gas chromatography method. Activation energies of these reactions were calculated.

Although all the inorganic additives catalyze the dehydration reaction, their mechanism of action is found to be different. $\mathrm{NH}_{4} \mathrm{Cl}, \mathrm{NH}_{4} \mathrm{H}_{2} \mathrm{PO}_{4}$ and $\mathrm{Na}_{3} \mathrm{PO}_{4}$ exert the strongest influence. 